\section{Pneumocystis carinii in a patient with pulmonary sarcoidosis and idiopathic $\mathrm{CD} 4+$ $\mathrm{T}$ lymphocytopenia}

\author{
A Sinicco, A Maiello, R Raiteri, \\ M Sciandra, G Dassio, C Zamprogna, \\ B Mecozzi
}

\begin{abstract}
A case of pulmonary sarcoidosis and idiopathic CD4 + T lymphocytopenia is reported. Pneumocystis carinii was detected in the bronchoalveolar lavage fluid of a young homosexual man who was asymptomatic without any evidence of congenital or acquired immunodeficiency but with a low CD4+ cell count. A clinical and histological diagnosis of pulmonary sarcoidosis was made. During follow up the patient had oral candidiasis and a CD4+ cell count persistently below $300 / \mu 1$. This case is highly suggestive of concurrent pulmonary sarcoidosis and idiopathic CD4+ T lymphocytopenia.

(Thorax 1996;51:446-447)
\end{abstract}

Keywords: sarcoidosis, HIV, CD4 + T lymphocytopenia.

Viral, bacterial, fungal, and parasitic infections can occur in patients with sarcoidosis. ${ }^{1-3}$ In particular, these infections are frequent in subjects with longstanding sarcoidosis or those treated with steroid or immunosuppressive

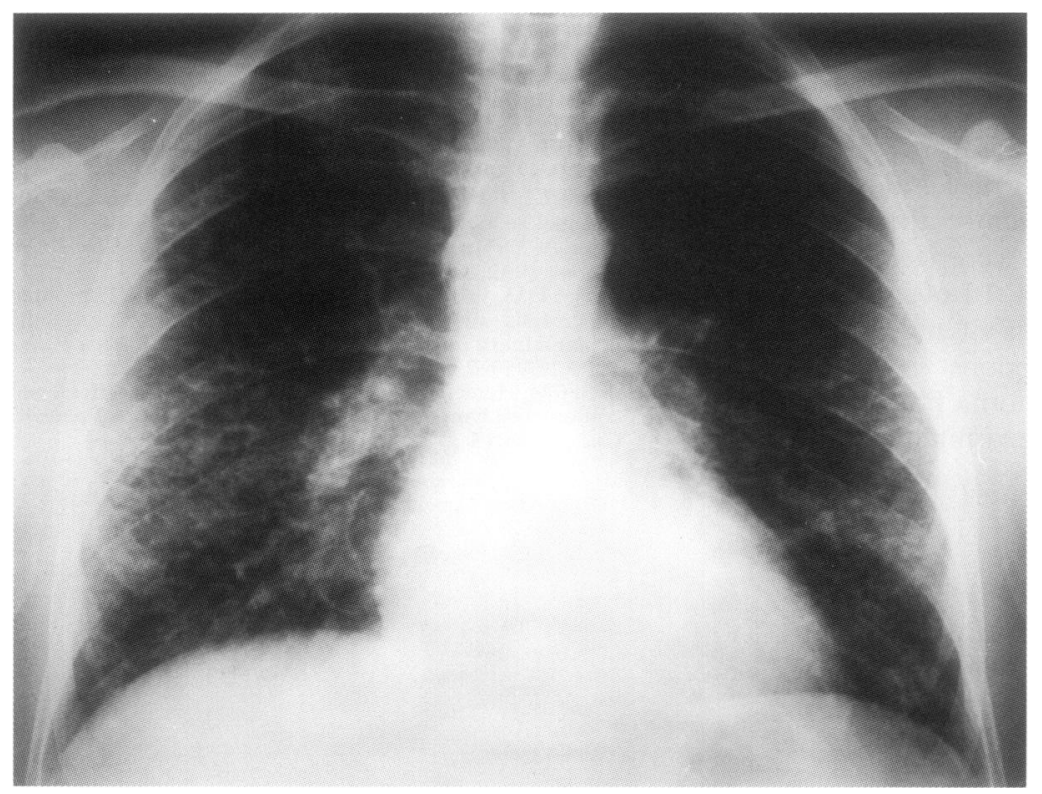

Chest radiograph showing reticulonodular infiltrates with hilar and paratracheal lymph node enlargement. therapy. ${ }^{4-5}$ Patients infected with HIV with coexisting sarcoidosis have recently been described, ${ }^{67}$ and unusual cases of opportunistic infections and CD4 $+\mathrm{T}$ lymphocytopenia in the absence of HIV infection have also been reported. ${ }^{8}$

We describe a case of pulmonary sarcoidosis in a young patient with unexplained CD4+ $\mathrm{T}$ lymphocytopenia.

\section{Case report}

A 27 year old non-smoking homosexual man was admitted in June 1993 to a dermatology ward for treatment of anal condylomata. The patient was asymptomatic with no chest illnesses. Routine haematological and biochemical screening was non-contributory. Physical examination was unremarkable but the admission chest radiograph (figure) showed diffuse nodular shadowing with hilar adenopathy. There was no history of immunosuppressive therapy or exposure to occupational dusts. The bronchoalveolar lavage (BAL) fluid tested positive for cysts of Pneumocystis carinii by blue toluidine $\mathrm{O}$ stain. The BAL fluid contained $89 \%$ macrophages and $10 \%$ total lymphocytes, with $8 \%$ CD $4+$ cells and $35 \%$ CD8 + cells. Bacteriological tests and cultures on the BAL fluid were negative for acid fast bacilli (AFB) and fungi. Direct fluorescent antibody (BFA) for Legionella was negative. The patient was given oral cotrimoxazole $(960 \mathrm{mg}$ three times daily for three weeks) and referred to the Institute of Infectious Diseases as an outpatient for supplementary evaluation. He was afebrile, not dyspnoeic or cyanosed. His body temperature was normal; respiratory rate was $19 / \mathrm{min}$; blood pressure was $100 / 70 \mathrm{~mm}$ $\mathrm{Hg}$, and heart rate 70 beats/min with a regular rhythm. There was no lymphadenopathy or peripheral oedema. Heart sounds, breath sounds, and neurological findings were normal. The abdomen was soft with no organomegaly. Antibody to HIV-1/2 (ELISA), HIV-1 p24 antigen assay (ELISA), Western blot analysis, amplification with the polymerase chain reaction for retroviral DNA sequences (PCR), and cell cultures for HIV were all negative. Likewise, standard serological tests for a variety of agents including respiratory syncytial virus, measles virus, influenza $A$ and $B$ viruses, parainfluenza 1, 2 and 3 viruses, adenovirus, enterovirus, parvovirus $\mathrm{B} 19$, coronavirus, $\mathrm{HBV}$, HCV, HTLV-I/II, HSV-1/2, CMV, EBV, Mycoplasma pneumoniae, Coxiella burnetii, Chlamydia psittaci, Rickettsia spp, and Treponema pallidum were all negative. $T$ cell subsets determined by flow cytometry demonstrated a severe immunodeficiency $(\mathrm{CD} 3+$ cells $=657 /$ $\mu \mathrm{l}, \mathrm{CD} 4+$ cells $=279 / \mu \mathrm{l}, \mathrm{CD} 8+$ cells $=437 / \mu \mathrm{l}$, $\mathrm{CD} 4+/ \mathrm{CD} 8+$ ratio $=0 \cdot 6)$. Anergy to delayed skin test antigens was present (Multitest Merieux).

Chest radiography showed a reticulonodular pattern with computed tomographic evidence of nodular and mediastinal adenopathy. A total body 67-gallium labelled scintiscan showed focal areas of grade 1 uptake only in the upper lobes bilaterally. Bronchoscopic examination 
was performed and revealed normal vocal cords, trachea, carina, and bronchi. No endobronchial lesions were noted. A new BAL fluid from the left upper lobe revealed negative DFA for Legionella, cultures for AFB and fungi, blue toluidine $\mathrm{O}$ stain for $P$ carinii. The BAL cell population consisted of $88 \%$ macrophages, $10 \%$ total lymphocytes, $10 \% \mathrm{CD} 4+$ cells, and $30 \%$ CD8 + cells. Histological examination of the transbronchial biopsy specimen revealed perivascular and interstitial, poorly formed, non-caseating epithelioid cell granulomas. All stains and cultures were negative for fungal, viral, and bacterial infections. Additional chemical laboratory investigation showed increased serum concentrations of angiotensin I converting enzyme (34 IU/l, normal value: $8 \cdot 3$ $21.4)$ and calcium $(11.4 \mathrm{mg} / \mathrm{dl}$, normal value: $8 \cdot 4-10 \cdot 7)$. There was no hypercalciuria or calcium deposits in the kidneys and bone radiology was normal. Serum $\beta_{2}$-microglobulin, 5'-neopterin and lactate dehydrogenase levels were also normal. Tests for autoimmune diseases were negative except for a small increase in circulating immunocomplexes $(30 \mu \mathrm{g} / \mathrm{ml}$, normal value: $<20)$ and antimyeloperoxidase antibodies $(3.3 \mathrm{U} / \mathrm{ml}$; normal value $<3 \mathrm{U} / \mathrm{ml})$. While selective IgA deficiency and other humoral immune defects were excluded, serum IgG subclasses revealed increased $\mathrm{IgG}_{1}(1200 \mathrm{mg} /$ $\mathrm{dl}$, normal value: 380-940) and $\mathrm{IgG}_{3}$ levels (121 mg/dl, normal value: $21-112$ ). Lung function studies were normal. Arterial blood gas tensions showed a small increase in arterial carbon dioxide tension $\left(\mathrm{PCO}_{2}=6.47 \mathrm{kPa}\right.$ breathing room air). Ocular evaluation and electrocardiogram were normal, as were ultrasonographic examinations of the parotid glands and the abdomen.

A diagnosis of pulmonary sarcoidosis was based on the presence of the clinical picture, no evidence of other granulomatous lung diseases, and typical non-caseating granulomas on biopsy. The patient was discharged and followed up without treatment.

About two months later he presented with oral candidiasis which responded to fluconazole (100 mg once daily for 10 days). Serology and cultures for HIV were negative and the lymphocyte subsets were still depleted $(\mathrm{CD} 3+$ cells $=$ $657 / \mu \mathrm{l}, \mathrm{CD} 4+$ cells $=285 / \mu \mathrm{l}, \mathrm{CD} 8+$ cells $=$ $386 / \mu \mathrm{l}, \mathrm{CD} 4+/ \mathrm{CD} 8+$ ratio $=0 \cdot 7)$. At two year follow up clinical and laboratory data were unchanged and the chest radiograph was stable with persistent infiltrates and mediastinal adenopathy. Serology to HIV-1/2, polymerase chain reaction, and cell cultures remained negative and lymphocyte depletion persisted with CD $4+$ cells below 300/ $\mu$ l.

\section{Discussion}

Sarcoidosis occurs in various immunodepressed conditions and many opportunistic infections have been recognised in these patients. $^{4-5}$ The association of $P$ carinii and sarcoidosis has never been reported. $P$ carinii, the most common cause of pneumonia in patients with AIDS, can occur in asymptomatic HIV positive subjects or in individuals with idiopathic CD4 + T lymphocytopenia. ${ }^{89}$

In our patient the colonisation of the lung by $P$ carinii was associated with severe lymphocytopenia and no clinical symptoms or evidence of infection on repeat HIV testing. Although the cause of sarcoidosis remains unknown, immunological alterations are associated with its pathogenesis. In particular, the CD4 + cell compartmentalisation at sites of disease may be responsible for the peripheral lymphocytopenia and involved in the pathogenesis of sarcoidosis. It has been suggested that immunosuppressed conditions may predispose to the development of sarcoidosis. ${ }^{10}$ This hypothesis may be consistent with our case, but we do not know whether the pulmonary sarcoidosis occurred before or after the CD4 + cell depletion. Whichever condition arose first, it is possible that the $\mathrm{T}$ cell pattern in the BAL fluid may be conditioned by the CD4 + T lymphocytopenia. As a result, an abnormal compartmentalisation of the lymphocyte subsets could occur at the sites of disease and influence the course of sarcoidosis, reducing the granuloma formation and the tissue involvement. Alternatively, the association between sarcoidosis and idiopathic $\mathrm{CD} 4+\mathrm{T}$ lymphocytopenia could also suggest that non $T$ cell mechanisms are involved in granuloma formation.

Even if lung colonisation by $P$ carinii, oral candidiasis, and anal condylomata were clearly linked to the low CD4 + cell count, no transmissible agents or immunosuppressive cause were found, but it is difficult to believe that pulmonary sarcoidosis alone could reduce and maintain the CD4 + cell below 300/ $\mu$ l. Over the past decade reports have been published regarding unexplained $\mathrm{CD} 4+\mathrm{T}$ lymphocytopenia without HIV in subjects with various opportunistic infections. ${ }^{9}$ We believe our patient meets the current case definition of idiopathic CD4 + T lymphocytopenia and that this may represent two independent clinical conditions in the same patient, both capable of influencing their natural history reciprocally.

1 Rottoli P, Bianchi-Bandinelli ML, Rottoli L, Zazzi M, Panzardi G, Valensin PE. Sarcoidosis and infections by human zardi $G$, Valensin PE. Sarcoidosis and infections

2 Rubinstein I, Baum GL, Rosenthal T. Fungal infections complicating pulmonary sarcoidosis. F Infect Dis 1985; 152:1360.

3 Ahmad I, Sharma OP. Sarcoidosis, cysticercosis and cryptococcosis: an unusual association. Sarcoidosis 1989;6:57-9. 4 Sahgal SM, Sharma OP. Fatal herpes simplex infection during chlorambucil therapy for sarcoidosis. $\mathcal{f} R$ Soc Med 1984;77:144-6.

5 Knox AJ, Wardman AG, Page RL. Tubercolous pleural effusion occurring during corticosteroid treatment of sarcoidosis. Thorax 1986;41:651.

6 Coots LE, Lazarus AA. Sarcoidosis diagnosed in a patient with known HIV infection. Chest 1989;96:201-2.

7 Newman TG, Minkowitz S, Hanna A, Sikand R, Fuleihan F. Coexistent sarcoidosis and HIV infection. A comparison of bronchoalveolar and peripheral blood lymphocytes. of bronchoalveolar and peril

8 Smith DK, Neal JJ, Holmberg SD and The Centers for Disease Control Idiopathic CD4 $+\mathrm{T}$ Lymphocytopenia Task Force. Unexplained opportunistic infections and CD4 + T lymphocytopenia without HIV infection. N Engl f Med 1993;328:373-9.

9 Elvin K, Lidman C, Tynell E, Linder E, Björkmann A. Natural history of asymptomatic and symptomatic Pneumocystis carinii infection in HIV infected patients. Scand $\mathcal{F}$ Infect Dis 1994;26:643-51.

10 Israel HL. Sarcoidosis, malignancy, and immunosuppressive therapy. Arch Intern Med 1978;138:907-8. 